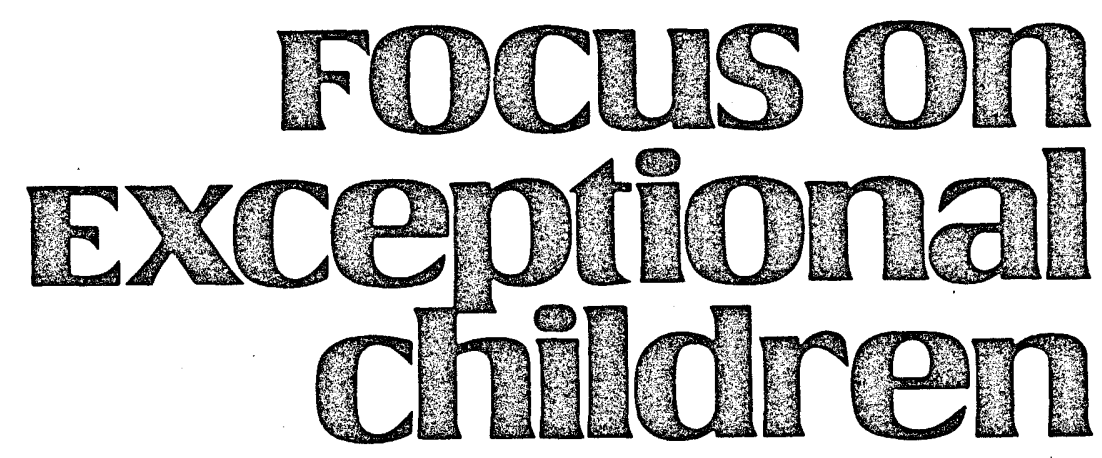

\title{
The Effects of Cultural and Linguistic Variables On the Academic Achievement of Minority Children
}

Joseph H. Whitaker and Alfonso G. Prieto

Research on bilingual/bicultural education and on bilingual/bicultural issues is broad and represents a variety of theoretical perspectives, which can be categorized into four general domains:

1. The effects of bilingualism and second-language acquisition.

2. The effects of bilingualism on social development and social interaction.

3. The effects of bilingualism on academic performance, cognition, and cognitive development (Rueda, 1983a, 1983b, 1985).

4. Theoretical considerations (Piagetian, linguistic, metacognitive, metalinguistic, and information processing) involved in language and cognition (Whitaker, 1988).

In relation to the last two areas of research, current theory proposes that certain features of the bilingual/bicultural environment may result in positive effects on the cognitive and academic performance of the bilingual/bicultural child. Additionally, a threshold level of language proficiency may be necessary for the positive cognitive effects of bilingualism to occur.

When factors other than specific disability or anomalous cognitive development (such as race, culture, or gender) are added to the research picture, however, many questions arise that are at present unanswered. For example: Should bilingual education be considered an available alternative for handicapped language minority children? Do certain groups of handicapped children have such a difficult time acquiring one language that bilingual programs should not be considered? If indeed certain cognitive advantages can be gained from proficiency in two languages, perhaps students in this group should have available the option of this potential remedial tool in conjunction with other interventions (Rueda, 1983a).

Obviously, before any decision can be made about the possibility of using bilingual/ bicultural education as an educational intervention with language minority handicapped children, the above questions must be addressed. But, more important, how bilingualism affects cognitive performance must be determined. The following review of the literature examines the research on bilingualism, language, cultural, and racial factors and how they relate to cognition, with special attention to the cases in which bilingualism and anomalous cognitive development are involved. 


\section{RESEARCH ON BILINGUALISM AND COGNITION}

A large number of studies have attempted to relate bilingualism specifically to cognitive development and academic achievement. In the following review these studies have been classified according to whether they support either positive or detrimental consequences of bilingualism. Then we will attempt to account for the discrepancies found in these diverse investigations.

\section{Negative or Mixed Effects of Bilingualism on Cognition}

An early study by Darcy (1946) reported significant differences between the mean IQ scores achieved by monolingual and bilingual subjects on the Stanford-Binet Intelligence Scale. These differences were consistent when subjects were divided according to age and gender and also when the age groups and genders were combined. Conversely, when differences in the mean IQs were determined for both language groups on the Atkins Object-Fitting Test (Atkins, 1931),

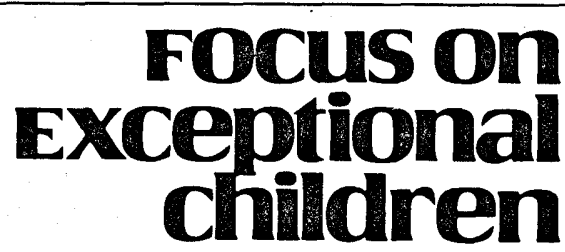

FOCUS ON EXCEPTIONAL CHILDREN (ISSN0015-51IX) (USPS 203-360) is published monthly except June, July, and August as a service to teachers, special educators, curriculum specialists, administrators, and those concerned with the special education of exceptional children. This publication is annotated and indexed by the ERIC Clearinghouse on Handicapped and Gifted Children for publication in the monthly Current Index to Journals in Education (CIJE) and the quarterly index, Exceptional Children Education Resources (ECER). It is also available in microform from Xerox University Microfilm, Ann Arbor, MI. Subscription rates: Individuals, \$24 per year; institutions, $\$ 30$ per year. Copyright (C) 1989 , Love Publishing Company. All rights reserved. Reproduction in whole or part without written permission is prohibited. Printed in the United States of America. Second class postage is paid at Denver, Colorado.

POSTMASTER: Send address changes to:

Love Publishing Company

Executive and Editorial Office

1777 South Bellaire Street

Denver, Colorado 80222

Telephone (303) 757-2579

EDITORIAL BOARD

$\begin{array}{cc}\begin{array}{c}\text { Edward L. Meyen } \\ \text { University of Kansas }\end{array} & \text { Glenn A. Vergason } \\ \text { Richard J. Whelan } \\ \text { Georgia State University }\end{array}$

significant differences in favor of the bilingual group were found. The differences were consistently in favor of the bilinguals when the groups were divided according to age and gender and also when the age groups and genders were combined.

The above results were substantiated by the differences found between the mean mental ages achieved by the two language groups on the Stanford-Binet and on the Atkins test. In every age and gender division the mental ages of the monolinguals surpassed those of the bilinguals on the Stanford-Binet scale, whereas on the Atkins test the performance of the bilinguals was consistently superior to that of the monolinguals.

The monolingual and the bilingual subjects of this study were matched closely as to number, gender, socioeconomic status (SES), and age within 6-month intervals. Further, the performance of the bilingual subjects was significantly inferior to that of the monolingual subjects on the StanfordBinet scale but significantly superior to the performance of the monolingual subjects on the Atkins test. Therefore, it may be concluded that the bilingual subjects tested using the Stanford-Binet in Darcy's (1946) investigation may have experienced language differences because performance on the Stanford-Binet would require subjects to have a substantial command of English.

Studies that claim to demonstrate the negative effects of bilingualism appear to suffer from a failure to adequately define bilingualism either operationally or theoretically, or to adequately control for language proficiency. Consequently, researchers such as Yela (1975) concluded that bilingualism reduced subjects' performance on semantic tasks. Brown, Fournier, and Moyer (1977) found that Mexican-American children scored significantly lower on tests that focused on science concepts and Piagetian concrete reasoning than did their Anglo-American counterparts. The population used in the Brown et al. (1977) study consisted of rural Colorado Mexican-American and Anglo-American fifth-graders. Identification of Mexican-American subjects was based on their having a Spanish surname or Spanish being spoken at home.

In an examination of the creative functioning of bilingual and monolingual third- through fifth-grade students using a regular and translated version of the Torrance Test of Creative Thinking (Torrance, Wu, Gowan, \& Aliotti, 1970), monolingual subjects scored significantly better on the measures of fluency and flexibility at every level. The bilingual group performed significantly better than the monolingual group on the measure of elaboration, although statistical significance was reached at only one grade level for the 
measure of originality.

A longitudinal study by Barik and Swain (1976) compared students receiving instruction in a French immersion program with students in the regular English programs. Three groups of students were evaluated annually using the OtisLennon Mental Ability Test. The immersion pupils outperformed the English-program students, although initial differences between the groups are difficult to attribute to language learning or type of program.

A comparison of the performance of Spanish-English bilinguals with English-speaking monolinguals on the PPVT and Raven's Coloured Progressive Matrices was done in a study by Myers and Goldstein (1979). Subjects were selected from intact classrooms at three levels (kindergarten, third, and sixth grades), in which all students were of low SES. Although there were no significant differences on the Raven's test between the two groups, the monolingual children performed significantly better than the bilingual students on the PPVT.

Using a Piagetian measure of conservation, De Avila and Pulos (1979) found no significant differences in performance between monolingual Spanish-speaking, monolingual English-speaking, and bilingual first-grade students. It was hypothesized that failure to find differences might have been due to the possibility that bilingual advantages may occur at an earlier or later stage of development or to the fact that balanced bilinguals were rare in the sample.

Gorrell, Bregman, McAllister, and Lipscomb (1982) compared two groups of bilingual students (VietnameseEnglish and Spanish-English) to a group of monolinguals on the block design subtest of the WISC-R and on three spatial role-taking tests of increasing complexity. The bilingual subjects were found to perform better than the monolinguals on the block design subtest but not on the measures of spatial role taking.

\section{Positive Effects of Bilingualism on Cognition}

Peal and Lambert (1962) designed a study to examine the effects of bilingualism on the intellectual functioning of children and to investigate the relationship between bilingualism, school achievement, and students' attitudes toward the second-language community. Bilinguals performed better than monolinguals on verbal and nonverbal intelligence tests-a clear reversal of previously reported findings (e.g., Darcy, 1946).

The French-English bilingual children who were subjects in the Peal and Lambert study, as a result of wider experiences in two cultures and languages, appeared to have advantages that the monolinguals did not. Experience with two language systems resulted in mental flexibility, superior concept formation, and more diversified set of mental abilities. On the other hand, monolingual children appeared to have a more unitary structure of intelligence, which they had to use for all types of inteliectual tasks. The bilingual children also were further ahead in school than the monolinguals, and they achieved significantly better than their classmates in the study of English. Their superior achievement in school appeared to be dependent on verbal facility.

In the previously mentioned study by Torrance et al. (1970), monolingual and bilingual Chinese and Malayan children in the third, fourth, and fifth grades of Singapore schools were administered Figural Form A of the Torrance Test of Creative Thinking (Torrance, 1966). Test booklets were translated into the subjects' native languages, and all instructions were given in the school's language of instruction, which was Chinese, Malayan, or English. Fluency, flexibility, and elaboration were scored using the standard guides for scoring all versions of this form of the test. A guide for scoring originality was based upon data from the Singapore culture, according to the same general principles as were used in developing the original scoring guide for the United States version of the test.

Overall, the monolinguals performed better than the bilinguals on fluency and flexibility, but the direction of the trend was reversed for originality and elaboration. The overall difference for elaboration was significant, but there was no significant difference for originality. If corrections are made for number of responses, the trend toward superiority of the bilinguals over the monolinguals on originality and elaboration becomes even stronger.

Ianco-Worrall (1972) designed several experiments to test Leopold's (1961) observations on the earlier separation of word sound from word meaning by bilingual compared to matched monolingual children. Attention to meaning or to sound of words was tested with the Semantic and Phonetic Preference Test, a two-choice test in which similarity between words could be interpreted on the basis of shared meaning or shared acoustic properties.

The notion that bilingualism leads to earlier realization of the arbitrary nature of name-object relationship was tested with the questioning technique developed by Vygotsky (1962). The technique calls for an explanation of names, whether names can be interchanged, and, when names are interchanged in play, whether the attributes of the objects change along with their names. The results supported Leopold's observations. Of the young 4- to 6-year old bilinguals, $54 \%$ consistently chose to interpret similarity between words in terms of the semantic dimension. 
The conclusion drawn is that bilinguals who are brought up in a two-language environment reach a relatively high level of semantic development 2 to 3 years earlier than their monolingual peers. A high percentage of the bilingual children perceived relationships between words in terms of their symbolic properties rather than their acoustic properties.

Application of Piagetian constructs to the study of bilingualism also can be found in the literature. The advantage of Piagetian tasks is that they can be administered so that the content of the task, but not necessarily the language in which the instructions are given, can be standardized, and also the experimenter can take care to assure that subjects understand the task at hand. This is certainly important when assessing the cognitive performance of groups for whom valid and reliable assessment has been a problem.

For example, Feldman and Shen (1971) designed a study to demonstrate that 5-year-old bilinguals have advantages that would be expected from their having two languages: in object constancy, in naming, and in the use of names in sentences. Additionally, it was suggested that object constancy should be in advance of naming (as Piaget suggested) and that naming should be in advance of using names in sentences. Specifically, monolingual and bilingual 5-yearold children were compared in their ability at tasks involving object constancy, naming, and use of names in sentences. These three tasks, which constitute a natural sequence of language skills, were all found to be easier for bilinguals than for monolinguals. This was most clear on nonverbal measures. Further analysis indicated that switching names in sentences was superior in bilinguals, but the knowledge of names and facility for acquiring new names was equivalent in the two groups.

A study by Liedtke and Nelson (1968) considered the experience of becoming bilingual at an early age and tested the effect on mental development. Certain aspects of concept development of bilingual and monolingual children then were compared. A test of concepts of linear measurements was constructed to serve as the primary instrument. The test (Concepts of Linear Measurement Test) consisted of six subtests, which dealt with the following aspects of linear measurement: (a) reconstructing relations of distance, (b) conservation of length, (c) conservation of length with change of position, (d) conservation of length with distortion of shape, (e) measurement of length, and (f) subdividing a straight line.

The resulting mean for the bilingual sample on the Concepts of Linear Measurement Test was significantly higher than the mean for the monolingual sample, which is in agreement with Peal and Lambert's (1962) finding that bilingualism has favorable effects on intellectual functioning. The mean for the bilingual sample on the conservation part of the test also was significantly higher than the mean for the monolingual sample. If the implication of the higher score is that the concept is more advanced and more highly developed, bilingual children manifest a better understanding of the concept as compared to monolingual children of the same age.

The mean for the bilingual sample on the measurement part of the test was significantly higher than the mean for the monolingual sample. This suggested that the measurement concept also had developed to a more advanced stage in the bilingual subjects.

Overall, the results seem to indicate that the linguistic and cultural experience of the bilinguals was an advantage. Additionally, the results indicate that being bilingual or becoming bilingual accelerates the normal process of some components of mental development.

\section{Limitations of the Research}

After a review of the above studies, results may be difficult to interpret because of the methodological errors in group assignment, controlling for language proficiency, and defining bilingualism. This includes failiure to control for linguistic variables and proficiency-specifically, a lack of the use of measures or controls for language proficiency. After considering the previously reviewed articles, the need for tighter linguistic control over the definition of bilingual and monolingual groups becomes readily apparent.

Results of the Feldman and Shen (1971) study, for example, are questionable because of the criteria for assignment to subject groups. Assignment to the bilingual group was made on the basis of the children's "understanding of several simple Spanish questions and ability to speak Spanish at home." Further, no information was provided concerning the nature of these questions or how the ability to speak Spanish at home was defined or ascertained.

Similarly, in the Liedtke and Nelson (1968) study, the criterion for assignment to the bilingual group was based on teacher observation. The group was defined as "children who had used two languages before entering school and who were exposed to both languages at home." No data were provided as to the actual level of proficiency for either the bilingual or monolingual groups. This study, like the Feldman and Shen (1971) one, was weakened by the lack of appropriate linguistic controls. 


\section{Research Controlling for Languages Proficiency and Bilingualism}

If bilingualism does accelerate cognitive functioning, the cognitive advantages of bilinguals should manifest themselves in studies that carefully control for language proficiency and that carefully operationalize and define bilingualism. These variables were carefully controlled in the Duncan and De Avila (1979) study on bilingualism and cognition, as reported in Table 1 . The primary purpose of the study was to assess the English/Spanish relative linguistic proficiency of four groups of Hispanic-background children in grades 1 and 3 and, on the basis of that assessment, to describe the relationship between degree of bilingualism and cognitive functioning, as measured by performance on a test of neo-Piagetian intellectual development and two tests of field dependence/independence.

An important finding of the Duncan and De Avila study was that the proficient bilingual children significantly outscored all other monolingual and limited-proficiency bilingual children on tasks of cognitive perspectivism and scored higher on tasks of cognitive perceptual components of fielddependent cognitive style. These findings clearly support the hypotheses regarding the advanced cognitive functioning of proficient bilinguals (Peal \& Lambert, 1962; Ianco-Worrall, 1972; Duncan \& De Avila, 1979; Cummins, 1978).

Cummins (1978) investigated the effects of bilingualism on the development of children's awareness of certain properties of language and on their ability to analyze linguistic input. Bilingual children at two grade levels (grade 3 and grade 6) demonstrated significantly greater awareness of the arbitrary nature of word-referent relationships and also were better able to evaluate nonempirical contradictory statements.

An important feature of the above examples is that they involve knowledge of linguistic processes. An even more important feature, however, is that the level of abstraction is free of content, and, as a result, metalinguistic or metacognitive awareness may not be necessarily related to any particular language or sociocultural circumstance and possibly can apply to other situations or experiences. One could expect, then, that the effects of bilingualism on cognitive or metacognitive processes might be manifest on other types of tasks. As a matter of fact, one of the primary features defining metacognitive and metalinguistic awareness is the individual's understanding of the arbitrary use of language.

More recent research has been conducted using subjects who have mild mental retardation. Rueda (1983b) examined the cognitive performance of children who are mentally retarded with moderate levels of language proficiency in Spanish and English in comparison to a matched group of monolingual English children. In spite of the study's limitations (small sample sizes, only moderate proficiency on the part of the bilingual subjects, and failure to measure the language skills of the monolingual sample), it was found that the bilingual group did not suffer any harmful effects as a result of exposure to two languages. In fact, there were differences in favor of the bilingual group on some items of the metalinguistic tasks.

Whitaker, Rueda, and Prieto (1985) compared the performance of three groups of 7- and 8-year-old mildly retarded children. Four dependent measures were used (three Piagetian tasks assessing conservation skills, reconstructive memory, recognitory memory, and one information processing task) to test the hypothesis that bilingualism would positively affect cognitive performance. Results indicated that the highproficiency bilinguals' performance was significantly superior on three of the four dependent measures.

\section{Summary of Research on Bilingualism and Cognition}

A summary of studies investigating the effects of bilingualism on various cognitive measures is presented in Table 1. As the previous discussion indicates, there is suggestion of both negative and positive effects of bilingualism on the educational, intellectual, and academic performance of language-minority students.

Several of the studies suffer from methodological and theoretical errors, including: (a) sample bias, (b) deficiency in sample selection with regard to the control of language proficiency, (c) test bias, and (d) procedural errors (Were subjects tested in their native language?). These errors may limit interpretation of the research.

From Table 1, it is apparent that differences in favor of bilinguals have been found in the studies that utilized Piagetian measures and metalinguistics measures. Theoretically, this has been explained by certain methodological factors such as control for language proficiency, and by certain features of the bilingual environment and experience. It includes the observation that Piagetian-based tasks may be better indicators of cognitive differences because they are not heavily language-dependent.

\section{EDUCATIONAL CONSIDERATIONS}

At this point we can attempt to tie the previously cited findings concerning bilingualism and cognition to the unique educational needs of the language minority/bilingual excep- 
TABLE 1

Positive and Negative Effects of Bilingualism on Cognitive Performance

\begin{tabular}{|c|c|c|c|c|c|}
\hline Author(s) & Date & \multicolumn{2}{|c|}{ Subjects } & Measures & Results \\
\hline Darcy & 1946 & \multicolumn{2}{|c|}{$2 \mathrm{yrs}, 6 \mathrm{mos}$} & $\begin{array}{l}\text { Stanford-Binet Intelligence Test } \\
\text { Atkins Object-Fitting Test }\end{array}$ & $\begin{array}{l}\text { Bilinguals scored lower } \\
\text { (Stanford). } \\
\text { Bilinguals favored (Atkins). }\end{array}$ \\
\hline Peal \& Lambert & 1962 & \multicolumn{2}{|c|}{10 -yr-olds } & $\begin{array}{l}\text { Lavoie-Laurendeau Group Test } \\
\text { Raven Progressive Matrices } \\
\text { Thurstone Primary Mental } \\
\text { Abilities }\end{array}$ & $\begin{array}{l}\text { Bilinguals performed better than } \\
\text { monolinguals on verbal and } \\
\text { nonverbal intelligence tests. }\end{array}$ \\
\hline Liedtke \& Nelson & 1968 & \multicolumn{2}{|l|}{$\begin{array}{l}\text { Grade } 1 \\
N=50\end{array}$} & Piagetian Concept Formation & Bilinguals performed higher. \\
\hline Torrance et al. & 1970 & \multicolumn{2}{|c|}{$\begin{array}{l}\text { 3rd, 4th, 5th } \\
\text { Graders }\end{array}$} & $\begin{array}{l}\text { Torrance Test of Creative } \\
\text { Thinking }\end{array}$ & $\begin{array}{l}\text { Monolingual-higher on fluency, } \\
\text { flexibility. Bilingual-higher on } \\
\text { elaboration; not significant for } \\
\text { originality. }\end{array}$ \\
\hline Feldman \& Shen & 1971 & \multicolumn{2}{|c|}{ 5-yr-olds } & $\begin{array}{l}\text { Object Constancy (Piagetian), } \\
\text { Naming, Sentences }\end{array}$ & $\begin{array}{l}\text { Bilinguals performed better on } \\
\text { all three tasks. }\end{array}$ \\
\hline lanco-Worrall & 1972 & \multicolumn{2}{|c|}{ 4-6-yr-olds } & Questioning Technique & $\begin{array}{l}\text { Bilinguals reach a stage of } \\
\text { semantic development } 2-3 \\
\text { years earlier than } \\
\text { monolinguals. }\end{array}$ \\
\hline Barik \& Swain & 1976 & \multicolumn{2}{|c|}{$\begin{array}{l}\text { Ss }^{*} \text { in French } \\
\text { Immersion } \\
\text { Program vs. } \\
\text { Regular } \\
\text { English } \\
\text { Program }\end{array}$} & Otis Lennon Mental Ability Test & $\begin{array}{l}\text { Immersion pupils out-performed } \\
\text { English program pupils. }\end{array}$ \\
\hline Brown et al. & 1977 & \multicolumn{2}{|c|}{$\begin{array}{l}5 \text { th Graders } \\
\mathrm{N}=150\end{array}$} & $\begin{array}{l}\text { Science Concepts Test } \\
\text { Piagetian Concrete Reasoning }\end{array}$ & $\begin{array}{l}\text { Bilinguals scored lower. } \\
\text { Bilinguals scored lower. }\end{array}$ \\
\hline Cummins & 1978 & \multicolumn{2}{|c|}{$\begin{array}{l}\text { Grade } 3 \\
N=80\end{array}$} & Language Objectivity & $\begin{array}{l}\text { Bilinguals show greater } \\
\text { awareness of arbitrary nature } \\
\text { of language. }\end{array}$ \\
\hline Duncan \& De Avila & 1979 & \multicolumn{2}{|c|}{$\begin{array}{ll}N=202 & \\
\text { Mex-Am } & N=54 \\
& \text { (Urban) } \\
\text { Mex-Am } & N=79 \\
\text { P.R.-Am } & N=45 \\
\text { Cuban-Am N } N=43 \\
\text { 1st-3rd grades }\end{array}$} & $\begin{array}{l}\text { Cartoon Conservation Scale (CCS) } \\
\text { LAS } \\
\text { Child Embedded Figures Test } \\
\text { Draw-A-Person }\end{array}$ & $\begin{array}{l}\text { Proficient bilinguals significantly } \\
\text { outperformed all other groups. }\end{array}$ \\
\hline
\end{tabular}


TABLE 1 (continued)

Positive and Negative Effects of Bilingualism on Cognitive Performance

\begin{tabular}{|c|c|c|c|c|}
\hline Author(s) & Date & Subjects & Measures & Results \\
\hline Myers \& Goldstein & 1979 & $\begin{array}{l}\text { Monolingual SPA } \\
\text { Monolingual ENG } \\
\text { Matrices } \\
\text { Bilingual }\end{array}$ & $\begin{array}{l}\text { PPVT } \\
\text { Raven Coloured Progressive }\end{array}$ & $\begin{array}{l}\text { No difference on Raven's. } \\
\text { Monolinguals outperformed } \\
\text { bilinguals on PPVT. }\end{array}$ \\
\hline De Avila \& Pulos & 1979 & $\begin{array}{l}\text { 1st Graders } \\
\text { Monolingual SPA } \\
\text { Monolingual ENG } \\
\text { Bilingual }\end{array}$ & Piagetian Measure of Conversation & $\begin{array}{l}\text { No significant differences } \\
\text { between the three groups. }\end{array}$ \\
\hline Gorrell et al. & 1982 & $\begin{array}{l}\text { Vietnamese-ENG } \\
\text { Spanish-English } \\
\text { Monolinguals }\end{array}$ & $\begin{array}{l}\text { WISC-RBlock Design } \\
\text { Three spatial role-tasks }\end{array}$ & $\begin{array}{l}\text { Bilinguals performed better on } \\
\text { block design but not on spatial } \\
\text { role-taking tasks. }\end{array}$ \\
\hline Rueda & 1983 & $\begin{array}{l}\text { Bilingual ENG- } \\
\text { SPA } \\
\text { Monolingual ENG } \\
\text { EMH }\end{array}$ & $\begin{array}{l}\text { Measures of Metalinguistic } \\
\text { Awareness }\end{array}$ & $\begin{array}{l}\text { Bilinguals performed equally, } \\
\text { if not better, on various tasks. }\end{array}$ \\
\hline \multirow[t]{2}{*}{ Whitaker etal. } & 1985 & $\begin{array}{l}\text { Bilingual ENG- } \\
\text { SPA } \\
\text { EMH }\end{array}$ & $\begin{array}{l}\text { Piagetian-Conservation, } \\
\text { Reconstructive Memory, } \\
\text { Recognitory Memory }\end{array}$ & $\begin{array}{l}\text { Proficient bilinguals performed } \\
\text { better than monolinguals on } \\
\text { three of four measures }\end{array}$ \\
\hline & & $\begin{array}{l}\text { Monolingual ENG } \\
\text { EMH }\end{array}$ & Information Processing & \\
\hline
\end{tabular}

tional child and point out some areas of continuing educational concern. The studies that reported negative educational, intellectual, and cognitive consequences for certain groups of bilinguals are indicators of practices that have caused minority children to be overrepresented in special education. Further, biased assessment instruments and practices and inadequate educational programs have done little to serve the needs of the students in question. Children from cultural and linguistic groups different from those of children in the majority culture, and particularly those from low SES environments, historically have been educationally underserved.

In making an effort to remedy these problems, attention to certain areas is crucial. These include, but are not limited to: (a) appropriately identifying and assessing the bilingual exceptional child, (b) alleviating the impact of biased assessment instruments and practices, (c) developing relevant and appropriate instructional programs and materials, (d) minimizing the impact of certain negative special education labels, (e) developing adequate bilingual and English as a Second Language (ESL) programs, and (f) modifying certain expectations and attitudes of teachers and administrators. Each of these areas of concern will be examined briefly.

\section{Appropriately Identifying and Assessing the Bilingual Exceptional Child}

The consequences of using inappropriate identification and assessment instruments, procedures, and techniques indeed can be quite serious for the bilingual exceptional child. One consequence of inappropriate procedures and instruments is overrepresentation in special education, which often leads to overall poor school progress for the bilingual exceptional child (Oakland, 1979; Mercer, 1971). Poor progress results from placement in programs that are unsystematic, inadequate, inappropriate, undeveloped, or simply nonexistent (Rodriguez, 1982; Baca, 1980). 
Adequate identification and assessment of the bilingual exceptional child must include factors such as language, culture, and socioeconomic status (Ambert, 1982). But few assessment instruments have been developed or modified that can assess, in a fair manner, different cultural and linguistic groups (Baca \& Bransford, 1982; Bernal, 1979; Ambert, 1982). Even if adequate instruments were available, a more serious problem exists: insufficient numbers of professionals have been adequately trained in administration and interpretation of such instruments (Hilliard, 1980; Ortiz, 1985). The situation is improving somewhat, though. For example, recent research has been conducted in identification of language disorders in Spanish-speakers (Ambert, 1986); techniques for minimizing inappropriate referrals of language minority students to special education (Ortiz \& Maldonado-Colón, 1986); methods of assessment and data interpretation of linguistically and culturally different students referred for disabilities or disorders (MaldonadoColón, 1986) and assessment of reading problems (Viera, 1986).

\section{Alleviating Bias in Assessment Practices}

As mentioned, one severe consequence of using biased instruments and assessment procedures results in overrepresentation of minority groups in special education (Mercer, 1974). Generally, such biased instruments and procedures fail to detect a distinct learning impairment but, rather, detect an inability to function adequately in English, which may result in special education placement because of cultural or dialectical differences (Ambert, 1982). An even more serious consequence, however, is that the placement is usually in a more restrictive special education program. This results in an associated problem of negative label impact (stigma, discrimination, embarrassment) and lowered teacher expectations (Jones, 1976). The pattern appears to be continuing.

\section{Developing Relevant and Appropriate Educational Programs}

Appropriate educational programs for the bilingual exceptional child, and in particular the preschool exceptional and

limited English-proficient (LEP) gifted and talented, are virtually nonexistent. But if any attempt were made to develop relevant and appropriate programs, certain considerations would have to be taken into account. For example, poor academic performance on the part of many bilingual exceptional children can be traced to curriculum that is historically and culturally irrelevant (Banks, 1981) and to IEPs that fail to address certain learner traits because of the nature of the IEP process (Ambert \& Dew, 1982). To partially alleviate this problem, Ambert and Dew (1982) suggest that:

\footnotetext{
IEPs for exceptional bilingual students specify: (a) instructional strategies which take into account linguistic facility, academic skill levels, modality and cognitive style preference; (b) the language(s) of instruction; (c) curricula, and materials designed specifically for linguistically and culturally diverse populations; and (d) motivators and reinforcers which are compatible with the learner's cultural and experiential background.
}

The language of instruction for bilingual exceptional children should be consistent with what is known about relationships between the native and the second language. For example, using the native language to promote certain conceptual skills may be more effective as a basis for the acquisition of English oral and literacy skills (Cummins, 1984).

Effective teaching skills, which involve utilization of both the native language (Spanish) and English can assist the teacher in mediating instruction and thus assist bilingual exceptional children's understanding of information and task expectations so they can obtain more accurate feedback regarding their performance (Omark \& Erickson, 1983; Baca \& Cervantes, 1984)

To minimize incompatibilities between bilingual exceptional children and standard school curricula, it is generally agreed that certain perspectives of the child's culture and heritage should be taken into account, although there is disagreement on exactly how they should be dealt with. As an example, some cultural and heritage enrichment programs appear to be compensatory in nature and reflect certain deficiencies in the home; as a result, care must be taken to adequately incorporate culture and heritage in the educational curriculum without adding any undue negative connotations (Banks, 1979).

\section{Minimizing Negative and Inappropriate Special Education Labels}

The impact of negative labels has concerned educators for some time (Dunn, 1968; Hobbs, 1975; McMillan, Jones \& Aloia, 1974). Additionally, the educational relevancy (aside from funding) of certain special education labels is increasingly being questioned (Howell \& Morehead, 1987).

Probably the most serious consequences of negative labels center on teacher expectations and student attitudes. As an 
example, Prieto and Zucker (1981) demonstrated that even special education teachers considered special education placement more appropriate for Mexican-American children than for their Anglo counterparts. Interestingly, some expectations seemed to take precedence over identical educational and psychological evaluation information in hypothetical case studies. Attempts to alleviate these problems should center on developing generic-type programs that emphasize academic skills and place less reliance on labels.

\section{Developing Adequate Bilingual and ESL Programs}

This concern focuses on the specific type of program established by the local education agency. It usually involves choosing between the transitional program and a maintenance program. But, as Rodriquez, Prieto, and Rueda (1984) have stated:

\footnotetext{
There are a variety of ways to describe the different types of programs that may be used. One way to address the problem is by "non-response," that is, to ignore that non-English speakers exist in the school. Another way can be termed "extinction," that is, to forbid the use of the non-English language.
}

In the area of ESL, a major theoretical difference involves the distinction between language learning and language acquisition, with acquisition being the generally preferred model. As Krashen (1982) explains, language acquisition takes place best when students are provided input that is comprehensible, interesting and relevant, not grammatically sequenced, and in sufficient quantity. Methods to accomplish this include Total Physical Response (Asher, 1972), "suggestopedia" (Bushman \& Madsen, 1976), and the Natural Approach (Krashen \& Terrell, 1982). For the bilingual exceptional child, these methods may offer language codes that are simplified and encourage more active involvement in the learning process.

\section{MODIFYING TEACHER-ADMINISTRATOR EXPECTATIONS AND ATTITUDES}

Teacher and administrator attitudes not only set the tone of the classroom but, more important, also shape and determine the nature of classroom interaction between student and teacher, and between students. Although the literature on precise effects of teacher expectations on the performance of minority and exceptional children is vague and controversial, evidence does suggest that teachers hold some negative attitudes toward minority-group children (Jones, 1976).
Certain student characteristics upon which teachers seem to base their negative expectations have been identified. These include low academic achievement, low SES, and, curiously, the use of nonstandard language, be it English or Spanish (Brophy \& Good, 1974).

The expectation that bilingual exceptional children will benefit from the regular mainstreamed classroom, particularly if this placement is with an inexperienced or insensitive teacher, could in the end be harmful to the student. Consequently, parents, teachers, and the student should be prepared well in advance of any such placements, with emphasis placed on the students' similarities rather than their differences.

Finally, Cummins (1986) has suggested that education reform is necessary if linguistic and culture-minority children are to succeed in school. According to him, this reform must include changes in (a) how teachers interact with students, (b) how the schools respond to minority communities, and (c) the general attitude of the dominant culture toward minority cultures within the society. Teachers must increase both oral and written communication with minority students and allow them to develop some responsibility for what they learn. Second, the schools have to develop better relationships with minority communities and encourage them to become involved in the decision-making processes that affect the educational experiences of their children. Third, the attitude of the dominant culture must begin to reflect equality toward minority culture rather than continue to view them as inferior. When these changes occur, minority children's educational experiences will be altered and the possibility of their academic success will increase.

\section{REFERENCES}

Ambert, A.N. (1982). The identification of LEP children with special needs. Bilingual Journal, 6(1), 17-22.

Ambert, A.N. (1986). Identifying language disorders in Spanish-speakers. Journal of Reading, Writing \& Learning Disabilities International, 2(1), 21-41.

Ambert, A.N., \& Dew, N. (1982). Special education for exceptional bilingual students: A handbook for educators. Milwaukee: Midwest National Origin Desegregation Assistance Center.

Asher, J.J. (1972). Children's first language as a model for second language learning. Modern Language Journal, 53, 3-17.

Atkins, R.E. (1931). The measurement of the intelligence of young children by an object-fitting test. Minneapolis: University of Minnesota Press.

Baca, L. (1980). Policy options for insuring the delivery of an appropriate education to bilingual/bicultural handicapped children. Reston, VA: Council for Exceptional Children.

Baca, L., \& Bransford, J. (1981). Meeting the needs of bilingual handicapped children. Momentum (pp. 26-29, 49-51). Boulder, CO: University of Colorado. 
Baca, L., \& Cervantes, H. (Eds.). (1984). The bilingual special education interface. St. Louis: Times Mirror/Mosby College Publishing.

Banks, J.A. (1981). Multi ethnic education: Theory and practice. Boston: Allyn \& Bacon.

Barik, H.C., \& Swain, M. (1976). A longitudinal study of bilingual and cognitive development. International Journal of Psychology, 11(4), 251-263.

Bernal, E.M. (1979). The education of culturally different gifted. Chicago: National Society for the Study of Education.

Brophy, J.E., \& Good, T.L. (1974). Teacher-student relationships: Causes and consequences. New York: Holt, Rinehart \& Winston.

Brown, R.L., Fournier, J.F., \& Moyer, R.H. (1977). A cross-cultural study of Piagetian concrete reasoning and sqience concepts among rural fifth-grade Mexican and Anglo-American students. Journal of Research in Science Teaching, 14, 329-334.

Bushman, R., \& Madsen, H. (1976). A description and evaluation of suggestopedia-a new teaching methodology. In J. Fanselow \& R. Crymes (Eds.), On TESOL ' 76 (pp. 29-38). Washington: TESOL.

Cummins, J. (1978). Bilingualism and the development of metalinguistic awareness. Journal of Cross-Cultural Psychology, 9(2), 131-149.

Cummins, J. (1984). Bilingualism and special education: Issues in assessment and pedagogy. Clevedon, Avon, England: Multilingual Matters, Ltd.

Cummins, J. (1986). Empowering minority students: A framework for intervention. Harvard Educational Review, 56(1), 18-36.

Darcy, N.T. (1946). The effects of bilingualism upon the measurement of the intelligence of children of preschool age. Journal of Educational Psychology, 37(1), 21-43.

De Avila, E.A., \& Pulos, S.M. (1979). Bilingualism and cognitive development. In M.K. Poulsen \& G.I. Lubin (Eds.), Piagetian theory: The helping professions. Los Angeles: University of Southern California Press.

Duncan, S.E., \& De Avila, E.A. (1979). Bilingualism and cognition: Some recent findings. NABE: The Journal for the National Association for Bilingual Education, 4(1), 15-50.

Dunn, L.M. (1968). Special education for mildly handicapped-Is much of it justifable? Exceptional Children, 46(8), 584-588.

Feldman, C., \& Shen, M. (1971). Some language-related cognitive advantages of bilingual five-year olds. Journal of Genetic Psychology, 118, 235-244.

Gorrell, J.J., Bregman, N.J., McAllister, H.A., \& Lipscomb, T.J. (1982). A comparison of spatial role-taking in monolingual and bilingual children. Journal of Genetic Psychology, 140, 3-10.

Hilliard, A.G. (1980). Cultural diversity and special education. Exceptional Children, 46(8), 584-588.

Hobbs, N. (1975). Issues in the classification of exceptional children. San Francisco: Jossey-Bass.

Howell, K.M., \& Morehead, M.K. (1987). Curriculum-based evaluation in special and remedial education. Columbus, $\mathrm{OH}$ : Merrill.

Ianco-Worrall, A.D. (1972). Bilingualism and cognitive development. Child Development, 43, 1390-1400.

Jones, R.L. (1976). Evaluating mainstream programs for minority children. In R.L. Jones (Ed.), Mainstreaming and the minority child. Reston, VA: Council for Exceptional Children.

Krashen, S. (1982). Principles and practice in second language acquisition. Elmsford, NY: Pergamon Press.

Krashen, S., \& Terrell, T. (1982). The natural approach: Language acquisition in the classroom. Elmsford, NY: Pergamon Press.

Leopold, W.F. (1961). Patterning in children's language learning. In S. Saporta (Ed.), Psycholinguistics. New York: Holt, Rinehart \& Winston.

Liedtke, W.W., \& Nelson, L.D. (1968). Concept formation and bilingualism. Alberta Journal of Education Research, 14(4), 225-232.

Maldonado-Colón, E. (1986). Assessment: Interpreting data of linguistically and culturally different students referred for disabilities or disorders. Journal of Reading, Writing, \& Learning Disabilities International, 2(1), 73-83.
McMillan, D.L., Jones, R.L., \& Aloia, G. (1974). The mentally retarded label: A theoretical analysis and the review of research. American Journal of Mental Deficiency, 79, 241-261.

Mercer, J.R. (1971). Sociocultural factors in labeling mental retardates. Peabody Journal of Education, 48, 188-203.

Myers, B., \& Goldstein, D. (1979). Cognitive development in bilingual and monolingual lower-class children. Psychology in the Schools, $16,137-142$.

Oakland, T. (1979). Research on the Adaptive Behavior Inventory for children and the estimated learning potential. School Psychology Digest, 8(1), 63-70.

Omark, P., \& Erickson, J. (Eds.). (1983). The bilingual exceptional child. San Diego: College-Hill Press.

Ortiz, A.A. (1985). Language and curriculum development for exceptional bilingual chlidren. In P. Chinn (Ed.), Education of culturally and linguistically different exceptional children. Reston, VA: Eric Clearinghouse on Handicapped \& Gifted Children.

Ortiz, A.A., \& Maldonado-Colón, E. (1986). Recognizing learning disabilities in bilingual children: How to lessen inappropriate referrals of language minority students to special education. Journal of Reading, Writing, and Learning Disabilities International, 2(1), 43-56.

Peal, E., \& Lambert, W.E. (1962). The relation of bilingualism to intelligence. Psychological Monographs, 76(27), 1-23.

Prieto, A.G., \& Zucker, S.H. (1981). Teacher perception of race as a factor in the placement of behaviorally disordered children. Behavior Disorders, 7(1), 34-38.

Rodriguez, R.F. (1982). The Mexican-American child in special education. Las Cruces, NM: Clearinghouse on Rural Education \& Small Schools.

Rodriguez, R.F., Prieto, A.G., \& Rueda, R.S. (1984). Issues in bilingual multicultural special education. NABE: Journal for the National Association for Bilingual Education, 8(3), 55-65.

Rueda, R. (1983a). Research in language and cognition with handicapped and non-handicapped bilingual children. Paper presented at Symposium on the Handicapped Hispanic Child: Research and Implications for Educational Practice, Texas A \& M University, College Station.

Rueda, R. (1983b). Metalinguistic awareness in monolingual and bilingual mildly retarded children. NABE: The Journal for the National Association for Bilingual Education, 8(1), 55-67.

Rueda, R. (1985). Cognitive development and learning in mildly handicapped bilingual children. In Chinn, P. (Ed.), Education of culturally and linguistically exceptional children. Reston, VA: Council for Exceptional Children.

Torrance, E.P. (1966). Torrance tests of creative thinking: Directions manual and scoring guide: Figural Test Booklet A. Princeton, NJ: Personnel Press.

Torrance, E.P., Wu, J., Gowan, J.C., \& Aliotti, N.C. (1970). Creative functioning of monolingual and bilingual children in Singapore. Journal of Educational Psychology, 6I(1), 72-75.

Viera, D.R. (1986). Remediating reading problems in a Hispanic learning disabled child from a psycholinguistic perspective: A case study. Journal of Reading, Writing and Learning Disabilities International, (2)1, 85-97.

Vygotsky, L.S. (1962). Thought and language. Cambridge, MA: M.I.T. Press.

Whitaker, J.H. (In press). Theoretical considerations in bilingualism and cognition. NABE: The Journal for the National Association for Bilingual Education.

Whitaker, J.H., Rueda, R.S., \& Prieto, A.G. (1985). Cognitive performance as a function of bilingualism in students with mental retardation. Mental Retardation, 26(6), 302-307.

Yela, M. (1975). Compresión verbal y bilingüismo. Revista de Psicología General y Aplicado, 30(6), 1039-1046. 


\section{What does Easter Seals do after Easter?}

The same thing we do before Easter... and before and after Christmas, the Fourth of July, Passover and Thanksgiving Day. Our services for people with disabilities continue all year long.

Our services include:

- Physical, occupational and speech-language therapies

- Vocational evaluation and training

- Camping and recreation

- Psychological counseling

- Prevention and screening for disabling conditions

- And much more.

Easter and other Holidays come and go. But Easter Seals is helping people every day to live independent and productive lives.

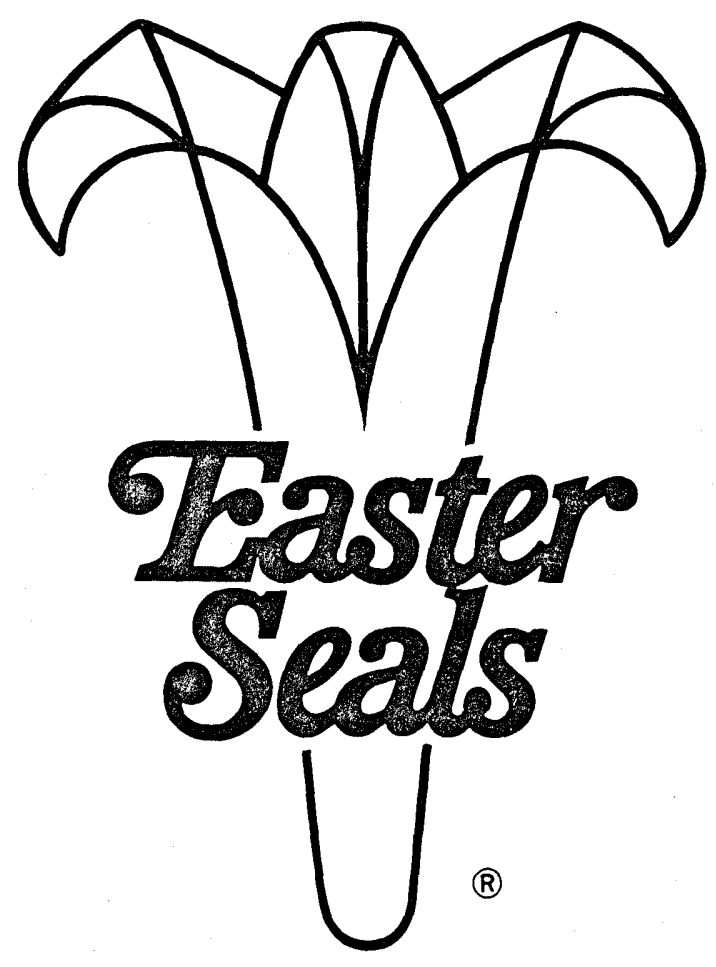

For more information on how you can be a part of it all, contact the Easter Seal Society in your community.

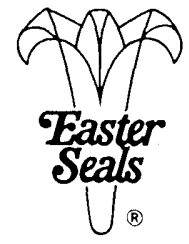

National Easter Seal Society

70 East Lake Street

Chicago, IL 60601

312/726-6200 (Voice)

312/726-4258 (TDD) 


\section{NEW STATISTICS}

\section{Students Served Under Chapter 1 of ECIA (SOP) and EHA-B by Handicapping Condition, 1986-87}

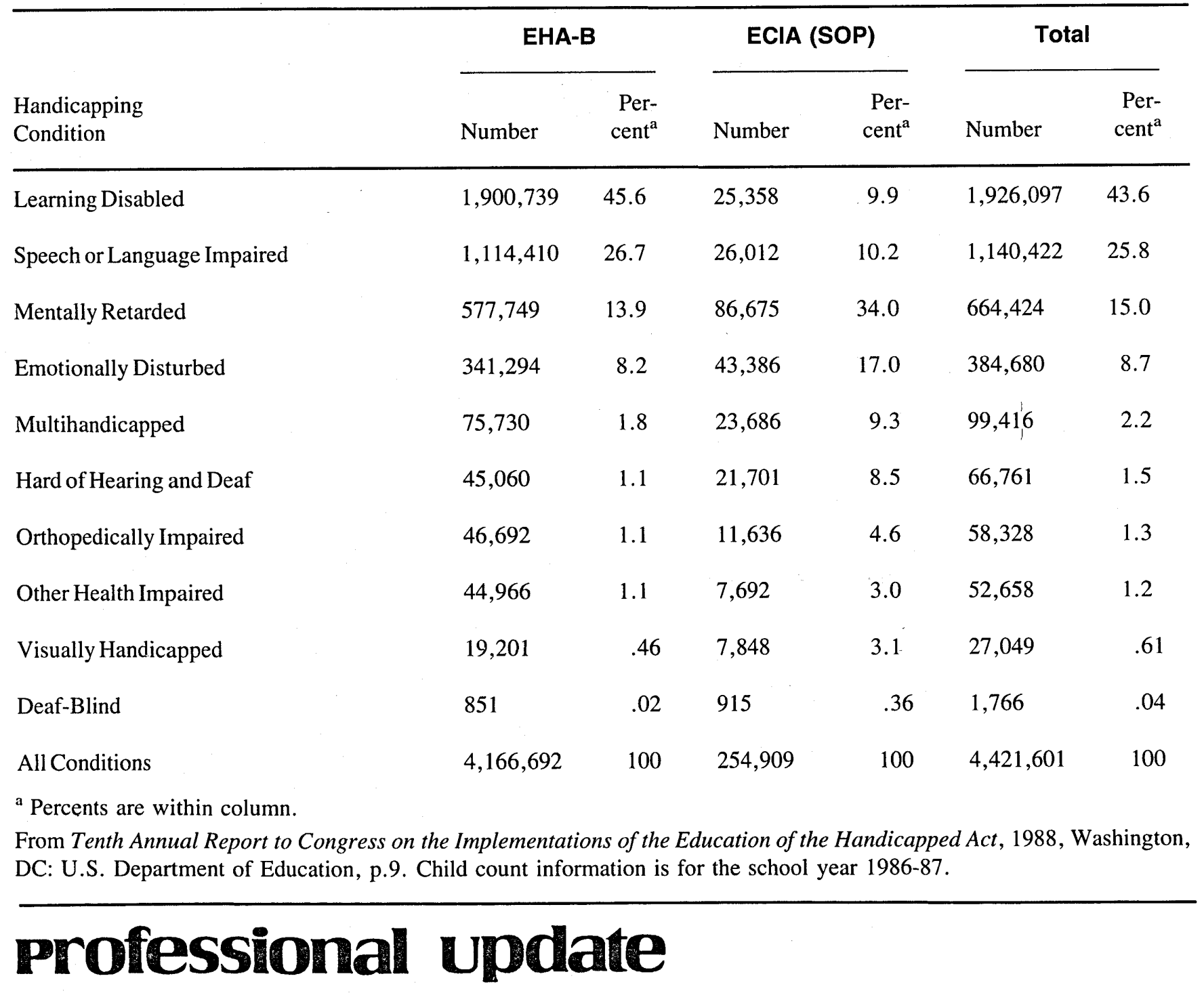

\section{UPCOMING MEETINGS}

\section{February 15-18, 1989}

Association for Children and Adults with Learning Disabilities

Fontainebleau Hilton

Miami Beach, FL

Contact: ACLD

(412) $341-1515$
}

\section{April 3-7, 1989}

Council for Exceptional Children

San Francisco, CA

Contact: CEC

(703) 620-3660 